\title{
CFD optimization of injection nozzles geometric dimensions of RHVT-machines in order to enhance the cooling capability
}

\author{
Adib Bazgir*, Ali Heydari \\ Petroleum University of technology, Department of Chemical Engineering, Ahwaz 6199171183, Iran
}

Corresponding Author Email: adib.bazgir@afp.put.ac.ir

https://doi.org/10.18280/ijht.360340

Received: 31 December 2017

Accepted: 29 May 2018

\section{Keywords:}

vortex tube, nozzle, temperature separation, numerical modeling, vortex chamber, reversed flows

\begin{abstract}
In this article, by using Computational Fluid Dynamic techniques, the optimized dimensions for injection nozzles of vortex tube machine are obtained. For this purpose, numerical simulation for different dimensions of length, width and height of nozzles is performed. However, other dimensions of modeled vortex tube are considered constant. The standard $\mathrm{k}-\varepsilon$ turbulence model was introduced to the governing equations for analyzing highly turbulence and compressible flows. The main goal of this study is to achieve the minimum amount of cold exit temperature by changing the dimensions of injection nozzles. In addition, an investigation is done upon pressure effect in the vortex tube chamber and its relation with the cold exit temperature and the best dimensions of nozzles are selected. Finally, some results of this article are validated by available experimental data. The comparisons show reasonable agreement.
\end{abstract}

\section{INTRODUCTION}

The vortex tube is an ingenious invention by two scientists George Joseph Ranque and Rudolf Hilsch which invented this instrument separately during the World War II in $1940^{\text {th }}$. After vortex tube discovery, A comprehensive study containing details about the way vortex tube is found, was reported which indicated that Ranque got confused Stagnation Temperature with Statics Temperature and that caused the instrument to fail. Figure 1 shows a schematic of the vortex tube.

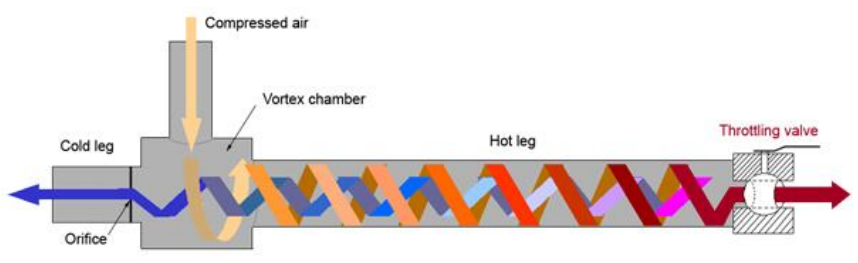

Figure 1. The schematic of the vortex tube

Ranque Theory explains that rotating gas flow expands on walls as a thick plane and its inner layers press outer layer by Eccentricity force and compress it which causes friction among layers to reach its minimum. Vortex tube refrigerator has many advantages over the conventional commercial refrigeration devices such as: simplicity, durability, smallness or lightness of weight, low cost, no need of electricity or chemicals, adjustability of temperature and more environmentally friendly [1-4]. It is Remarkable that vortex tubes are classified as two kinds in locating their cold outlet. The first kind is counter-flow vortex tube which has inlet part with center perforated nozzles, a warm tube and a conical control valve. The second kind is Uni-flow vortex tube and has a similar process like counter-flow but in this case, cold and hot air exits are eccentric. Vortex tube has extensive applications in local cooling (spot cooling) for a variety of machines, production lines and processes. The first experimental study was done in 1967 by Lindstrom-Lang [5] and Marshall [6] in 1977. Working fluids used in their experiment included Oxygen and nitrogen, carbon dioxide and helium, carbon dioxide and air and much more components. In 2001, vortex tube was used as CO2 separator system by Raterman et al. [7]. In 2002, Kulkarni and Sardesai [8], used it to dilute methane gas. In 2004, Poshernev and Khodorkov [9] used methane as working fluid and turned into the liquid through vortex tube. In 1979, Takahama et.al. [10] used water vapor and at the same time, two-phase propane was used by Collins and Lovelace [11]. They realized that when the degree of dryness (mass ratio of gas to total mass) of propane is higher than 0.8 , it gives a significant temperature difference. Gao et.al. in 2005 [12], and Eiamsa-ard and Promvonge [13] in 2008 are also done experimental cases in this field. In 2007, Wu et al. [14] designed a new nozzle based on Mach number study inside vortex chamber to significantly reduce energy loss. Kirmaci and Uluer [15] studied key parameters in 2009. In their experiment, 5 different quantities of cold outlet diameter were tested for 2, 3, 4, 5, 6 inlet nozzles. Cold outlet temperature was obtained from minimum to maximum amount respectively for 2, 3, 4, 5, 6 nozzles. This experiment states that 3 nozzles tube has the best performance and 6 nozzles tube has the worst efficiency. Pinar et al. [16] used Taguchi method to investigate vortex tube performance for a different number of nozzles and fluid type in different outlet pressure. These experiments resulted in that maximum temperature difference occurs for minimum nozzles (2). In 2010, Dincer et al. [17] investigated Exergy and vortex tube performance for different inlet nozzle cross-section areas $(3 \times$ $3,4 \times 4,5 \times 5 \mathrm{~mm}^{2}$ ) under performing pressure of 260 to 300 $\mathrm{KPa}$. The maximum temperature difference was gained in $3 \times$ $3 \mathrm{~mm}^{2}$ cross-section area. In 2011, Polat and Kirmaci [18] used a mathematical method called PFSAR for experimental data analysis. In their executed experiments, different types of inlet gases, number of nozzles and inlet pressure were studied. In 
2011, Chang et al. [19] worked on parameters such as angle of tube divergence, length of divergent vortex tube and number of inlet nozzles. They concluded that increment of inlet nozzle number highly influences temperature reduction sensitivity in vortex tube and obtaining its highest amount. Lewellen [20] used numerical simulation and experimental studies to investigate above theory and concluded that energy separation is actually the effect of inner friction, and defined turbulence based on turbulent viscosity. Ahlborn and Groves [21] offered secondary circulation model based on their experiments. They realized that accumulated mass flow in vortex tube cross section in cold outlet section is more than cold outlet flow rate and this explains a secondary circulation in the vortex tube. With developing computers and their utilization in science and development of numerical methods, application of CFD technique became more interesting among scientists. The numerical method reduces twist of experimental works and also improves our concepts about the physics of the problem. Bramo and Pourmahmoud [22-24] checked out the effect of length on stagnation point location in 2010 and 2011. Using a numerical simulation with lengths $92,106,120,230,350$ and $400 \mathrm{~mm}$, the effect of stagnation point spot in tube's length on the amount of energy separation in the vortex tube has been investigated. They concluded that in $106 \mathrm{~mm}$ length, stagnation point location is more near to hot outlet than other models and this specific model generates the most temperature difference between hot and cold outlet. Numerical works on a number of inlet nozzles in vortex tube are very less than experimental researches. In 2010, Shamsoddini and Hossein Nezhad [25] numerically studied a number of nozzles effect. They showed that addition of nozzles improves cooling power and this corresponds to a reduction of cold outlet temperature but this increment is so slight. In 2009, Akhsameh and Pourmahmoud [26] numerically investigated the effect of geometric parameters like profile and number of inlet nozzles including 2, 3 and 6 direct convergent nozzles and a helix nozzle, diameter of cold outlet and ratio of length to the diameter on the amount of energy separation. Based on their results, vortex tube with $6.2 \mathrm{~mm}$ outlet diameter and ratio of length to a diameter equal to 20 and 6 convergent nozzles generates the highest separation energy. Basically, most of the current researches are focusing on different essential parameters in vortex tube design and its effect on vortex tube performance. In recent years technique of Computational Fluid Dynamics (CFD) and numerical simulation are developed to give a more accurate explanation of energy separation phenomenon in the vortex tube. Many types of research are done about gas injection nozzles in the vortex tube but most of them were experimental and the object was number of nozzles, not nozzle profile. There are a few types of research in numerical field and CFD, so an extensive investigation seems necessary. This paper tries to optimize the geometric parameters of the injection nozzles and reports a comprehensive set of data concerning improving the thermal separation inside vortex tube. Moreover, there were researchers who worked on cooling using different methods. Seyed Ehsan Rafiee [27] experimentally investigated cooling process within DCTV systems. Atsushi Tsutsumi and Yasuki Kansha [28] investigated heat circulation systems for continuous heating and cooling process.

\section{GOVERNING EQUATIONS}

Vortex tube numerical model is simulated by Fluent Code and principal equations are solved in three-dimensional compressible turbulent fields. Considering that flow inside vortex tube is highly turbulent, in addition to equations of mass conservation, momentum, energy and gas equation of state, a turbulent model should be used for the effect of turbulence. Three-dimensional flow field equations for mass conservation, momentum conservation, and energy conservation are written below:

$\frac{\partial}{\partial x_{j}}\left(\rho u_{j}\right)=0$

$\frac{\partial}{\partial x_{j}}\left(\rho_{u_{i} u_{j}}\right)=-\frac{\partial p}{\partial x_{i}}+\frac{\partial}{\partial x_{j}}\left[\mu\left(\frac{\partial u_{i}}{\partial x_{j}}+\frac{\partial u_{j}}{\partial x_{i}}-\frac{2}{3} \delta_{i j} \frac{\partial u_{k}}{\partial x_{k}}\right)\right]+\frac{\partial}{\partial x_{j}}\left(-\overline{\rho u_{i}^{\prime} u_{j}^{\prime}}\right)$

$\frac{\partial}{\partial x_{i}}\left[u_{i} \rho\left(h+\frac{1}{2} u_{j} u_{j}\right)\right]=\frac{\partial}{\partial x_{j}}\left[k_{\text {eff }} \frac{\partial T}{\partial x_{j}}+u_{i}\left(\tau_{i j}\right)_{e f f}\right]$,

$k_{\text {eff }}=K+\frac{c_{p} \mu_{t}}{\operatorname{Pr}_{t}}$

Because working fluid is air, an ideal gas is used for simulation.

$p=\rho R T$

It is considered that in this numerical simulation finite volume method is used to solve governing equation. For high accuracy of calculations, discretization of transfer and distribution terms is done by second-order upwind method and because fluid is assumed compressible, a SIMPLE algorithm is used to associate pressure and velocity field. Actually, we should mention that this algorithm is used to couple velocity and pressure in separation solving method at steady state calculations, which uses the relation between velocity and pressure reforms to fulfill mass conservation law and obtain pressure field. To solve equations, a famous solution named separation solver is used. In this solving algorithm, governing equations respectively will be solved. In other words, they are separated. These equations are not linear but continuous, so many iterations in solving loop should be applied. The related algorithm is shown in Figure 2 .

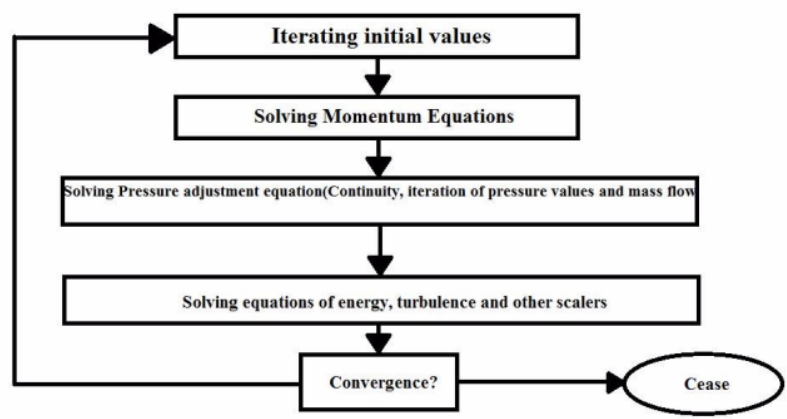

Figure 2. The related algorithm

The number of pages for the manuscript must be no more than ten, including all the sections. Please make sure that the whole text ends on an even page. Please do not insert page 
numbers. Please do not use the Headers or the Footers because they are reserved for the technical editing by editors.

\section{TURBULENCE SIMULATION}

As indicated before, flow inside vortex tube is highly turbulent [26]; Therefore, a proper turbulence model should be considered for simulation. Some researches of scientists such as references [29-31], all verified better and more like experimental results in well-known turbulence k- $\varepsilon$ model with respect to other turbulence models such as k- $\omega$ and SST. According to reports in above references, presented standard turbulence $\mathrm{k}-\varepsilon$ model which is used to simulate flow turbulence in this paper brings more accurate results with respect to Renormalization Group $\mathrm{k}-\varepsilon$ Model (RNG) and Reynolds Stress Model (RSM). Comparison of current numerical simulation results shows a great agreement of turbulence $\mathrm{k}-\varepsilon$ model with experimental results but just in case, turbulence $\mathrm{k}-\omega$ and SST models will be investigated in continue and results will be compared. Equations related to turbulence k- $\varepsilon$ model are brought in equations 5 and 6 . In these equations, $\mathrm{k}$ represents Turbulence Kinetic Energy and $\varepsilon$ represents its dissipation rate, so $\mathrm{k}$ and $\varepsilon$ will be determined by these transfer equations:

$\frac{\partial}{\partial t}(\rho k)+\frac{\partial}{\partial x_{i}}\left(\rho k u_{i}\right)=\frac{\partial}{\partial x_{j}}\left[\left(\mu+\frac{\mu_{t}}{\sigma_{k}}\right) \frac{\partial k}{\partial x_{j}}\right]+G_{k}+G_{b}-\rho \varepsilon-Y_{M}$

$\frac{\partial}{\partial t}(\rho k)+\frac{\partial}{\partial x_{i}}\left(\rho k u_{i}\right)=\frac{\partial}{\partial x_{j}}\left[\left(\mu+\frac{\mu_{t}}{\sigma_{\varepsilon}}\right) \frac{\partial \varepsilon}{\partial x_{j}}\right]+C_{1 \varepsilon} \frac{\varepsilon}{k}\left(G_{k}+C_{3 \varepsilon} G_{b}\right)-C_{2 \varepsilon} \rho \frac{\varepsilon^{2}}{k}$

In these equations $G_{\mathrm{k}}$ represents Generation of Turbulence Kinetic Energy due to the Mean Velocity Gradients, $G_{\mathrm{b}}$ shows Generation of Turbulence Kinetic Energy due to Buoyancy and $Y_{\mathrm{M}}$ is a symbol of velocity Fluctuations in the compressible turbulent flow. $\mathrm{C}_{2 \varepsilon}, \mathrm{C}_{1 \varepsilon}$ and $\mathrm{C}_{3 \varepsilon}$ are constant coefficients determined by the fluent guide:

$\mathrm{C}_{1 \varepsilon}=1.44, \mathrm{C}_{2 \varepsilon}=1.92$

${ }_{\mathrm{k}} \sigma$ and ${ }_{\varepsilon} \sigma$ are expressions of turbulence Prandtl number respectively for $\mathrm{k}$ and $\varepsilon$ considered as below:

$\sigma_{\mathrm{k}}=1.0, \sigma_{\varepsilon}=1.3$

Turbulence viscosity $\mu$ is calculated by $\mathrm{k}$ and $\varepsilon$ :

$\mu_{t}=\rho C_{\mu} \frac{k^{2}}{\varepsilon}$

$\mathrm{C}_{\mu}$ is constant and can be determined as:

$\mathrm{C} \mu=0.09$

\section{GEOMETRIC DESCRIPTION OF THE SIMULATED VORTEX TUBE}

GAMBIT $^{\mathrm{TM}}$ software is used to mesh flow field and to analyze flow field, fluent software standard code is applied. CFD modeling of question is created due to dimensions and geometric properties of the experimental model by Sky et al. [32]. In this model, inlet includes 6 separate nozzles and the hot outlet is simulated as a flat plate. For three-dimensional modeling, Block-Structured Mesh is applied to create a network which Figure 3 shows generated network considered for three-dimensional simulations. Because flow in vortex tube is high turbulence and compressible; therefore, requires the generation of a tiny network for the fluid field which fluid field network is considered high dense because of quick changes and high gradient near inlet and outlet, and finally a very small dense field is created for fluid flow. In consequence, this process requires high-speed processing computers. Hence, to reduce analysis time taken, a three dimensional Periodic and Rotational Periodic Boundary model is simulated which according to the symmetry of fluid field and presence of 6 nozzles, it only requires a 60 angle sector of the fluid field with periodic boundary conditions for analysis which is shown in Figure 3.

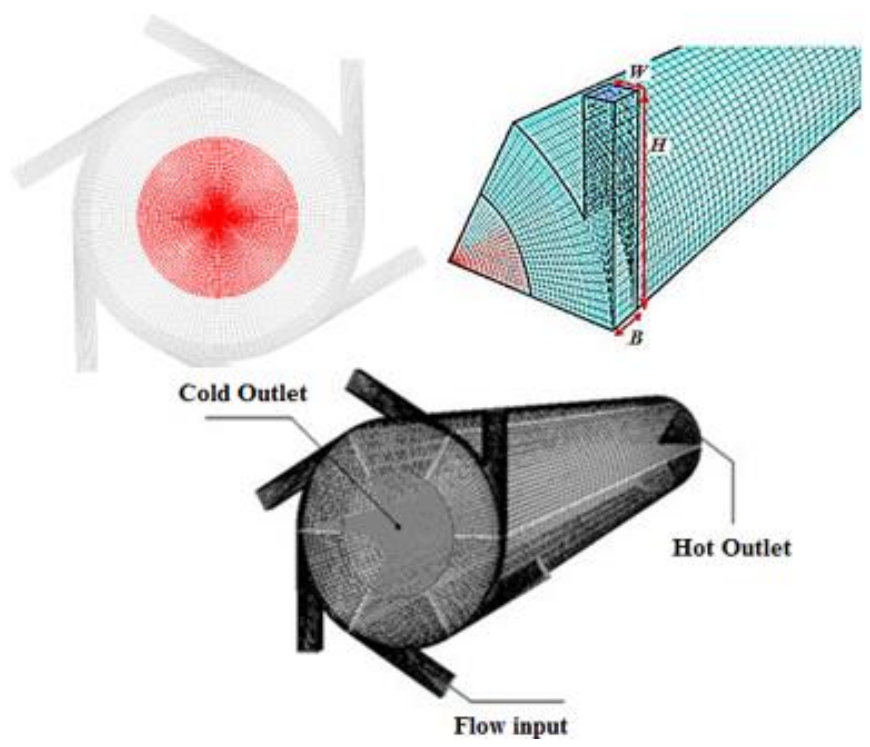

Figure 3. Mesh generated network considered for threedimensional simulations

Simulated model in this paper is first compared with experimental simulation and numerical model of the sky et al. [32] with consideration of the least cold outlet temperature determination in cold mass fraction at $\alpha=0.3$, hence this cold mass fraction is chosen as Maximum Cooling Effect and will be a criterion for investigations and comparison in most cases. Table 1 shows geometric properties of the simulated model.

Table 1. Geometric properties of the simulated model

\begin{tabular}{cc}
\hline Parameter & value \\
\hline Pipe length & $106 \mathrm{~mm}$ \\
\hline Diameter pipe & $11 / 4 \mathrm{~mm}$ \\
\hline The total cross-sectional area of the nozzle & $\mathrm{mm}^{2}$ \\
entrance & $7 / 66$ \\
\hline Cool outlet diameter & $6 / 2 \mathrm{~mm}$ \\
\hline Hot outlet cross section & $95 \mathrm{~mm}^{2}$ \\
\hline
\end{tabular}

\section{BOUNDARY CONDITIONS}

\subsection{Inlet}

According to CFD model used by sky et al. [32], Mass Flow Inlet boundary condition is applied for inlet boundary to vortex 
tube which is specified with the total mass flow, stagnation temperature, and direction of inlet flow vector. Due to existing experimental results, applied conditions on inlet are approximately fixed. During the investigation, inlet boundary condition is considered as constant inlet mass flow rate $\left(\dot{m}_{i n}\right)$ equal to 9.34 g.s ${ }^{-1}$ for applied pressure equal to 4.8 bar and stagnation temperature is assumed to equal to $294.2 \mathrm{~K}$. Also the direction of inlet flow vector is supposed to be normal to inlet boundary.

\subsection{Cold exit end}

Pressure Outlet boundary condition is applied at the cold exit end. In other words, the static pressure in cold exit is assumed as known and is determined based on experimental results [32]. According to experimental results, pressure can be assumed very low in the cold exit. In this numerical study, the pressure is experimentally determined $15895 \mathrm{~Pa}$. In low mass fractions in cold exit CFD simulation indicates a reversed flow in air cold outlet flow. Therefore reversed flow temperature must be determined. Many different ways are found in references to determine reversed flow temperature and this numerical study used validity published articles to calculate reversed flow temperature, therefore mean temperature of cold outlet flow is equal to reversed flow temperature. For the current study, reversed flow temperature is assumed $290 \mathrm{~K}$.

\subsection{Hot exit end}

For hot exit end such as cold exit end, the outlet pressure boundary condition is applied. The difference is that pressure in hot exit is assumed a repetitive variable until desired mass fraction in cold exit is obtained.

\subsection{Vortex tube wall}

For solid surfaces, no-slip boundary condition is used; therefore, all velocity components in walls are zero. Also, these surfaces are assumed as adiabatic. The Periodic boundary condition is used in shear cross-sections due to flow symmetry and geometry.

\section{GRID INDEPENDENCY STUDY}

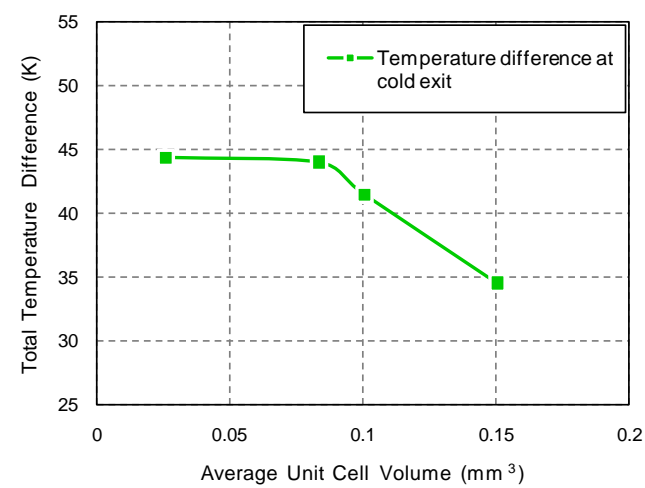

Figure 4. Studying the independence of the mesh on the basis of maximum cold temperature separation

To omit and reduce any deviation caused by largeness or improper dimensions of fluid field meshing and independence of result analysis from numerical model meshing, simulation was done by different meshing numbers to study the effect of mesh numbers, and concluded that deviation in results were too less for element volumes less than $0.0275 \mathrm{~mm} 3$ (number of elements more than 160000). In consequence, due to the approximate stability of results that indicates independence of results analysis from meshing influence, the same number of elements are used to reduce the time taken by calculates. To study other models with varying nozzles, tried to use elements with a mean volume of studied model elements for independence from the mesh. Results are shown in Figure 4 and 5 .

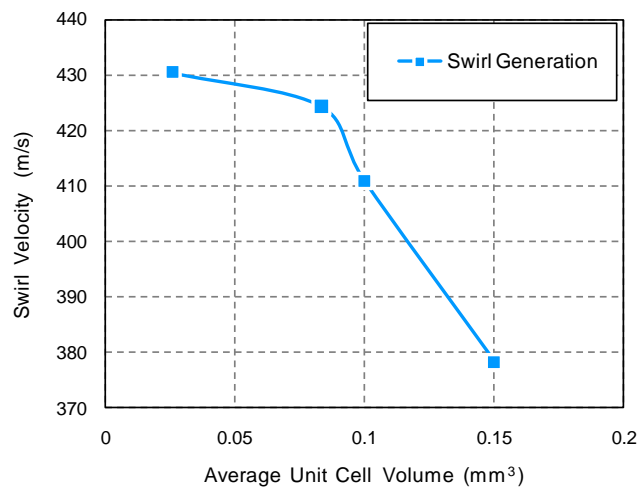

Figure 5. Independence study of meshing based on maximum swirling velocity in the rotary enclosure

\section{VERIFYING TURBULENCE MODEL}

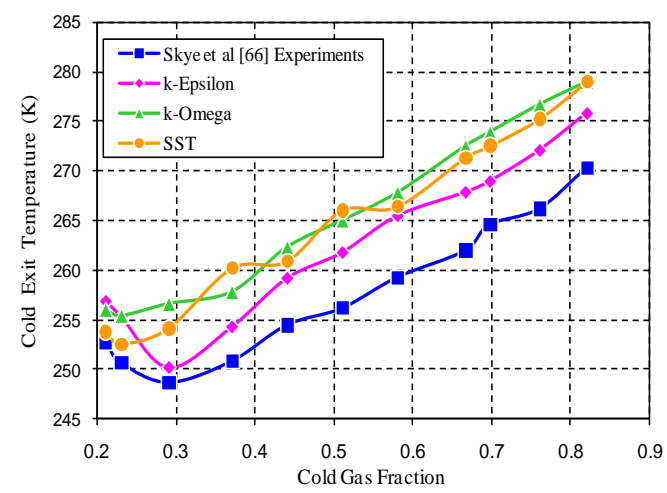

Figure 6. Gas temperature at the cold outlet for different turbulence models

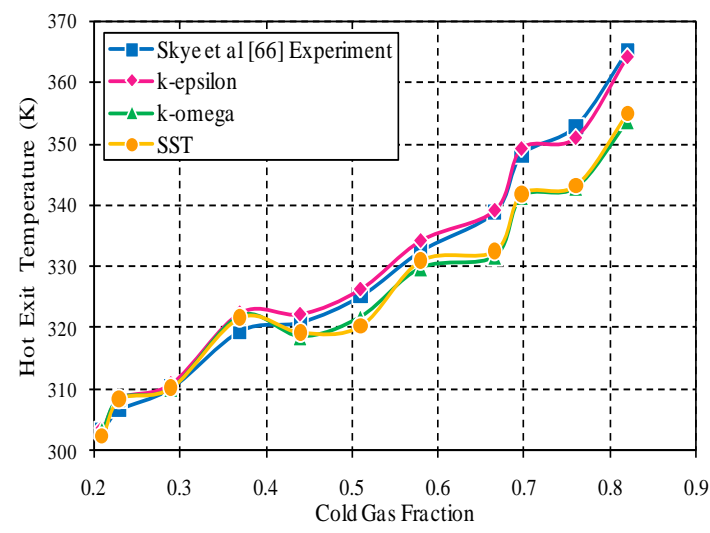

Figure 7. Gas temperature at the hot output for different turbulence models 
As stated before, the considered model is a threedimensional simulation with axial symmetry by applying turbulence models $\mathrm{k}-\varepsilon, \mathrm{k}-\omega$ and SST to simulate flow turbulence in order to investigate the effect of each turbulence model in energy separation phenomenon for swirling compressible flow. This study tried to simulate the model with other turbulence models such as k- $\varepsilon, \mathrm{RNG}$ and RSM which for considered geometry, applying these turbulence models were assessed with divergence in solution. Comparison of results obtained by current numerical simulation shows a great agreement between turbulence model $\mathrm{k}-\varepsilon$ with experimental results. Figure 6 and 7 compare temperature separation in hot and cold outlets granted by different turbulence models with experimental results of sky et al. [32]. As shown in Figure 6 and 7 , in most of the turbulence model, the calculated temperature for the hot gas outlet $\left(T_{h}\right)$, has a great conformity with experimental results while data for cold gas outlet temperature $\left(T_{c}\right)$ by k- $\varepsilon$ agrees with experimental data.

\section{VALIDATION OF NUMERICAL SIMULATIONS}

Results gained by numerical modeling are compared with experimental results [32] and all comparisons are reported based on the mass fraction in cold outlet. Figure 8 shows a comparison of temperature separation in cold outlet. As observed, temperature separation granted by the numerical model in cold outlet is approximately $37 \mathrm{~K}$ at minimum cold mass fraction which increases to $44 \mathrm{~K}$ with the addition of cold mass fraction up to 0.3 . After this point, additional cold mass fraction brings a reduction of temperature separation.

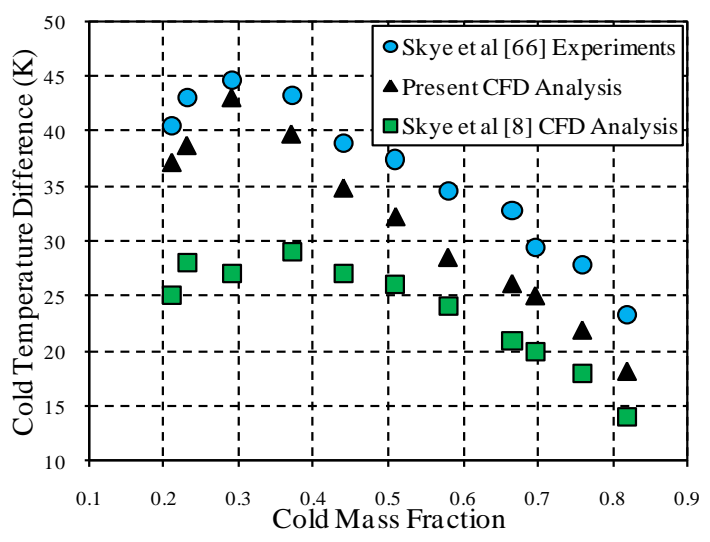

Figure 8. Temperature separation obtained at a cold outlet

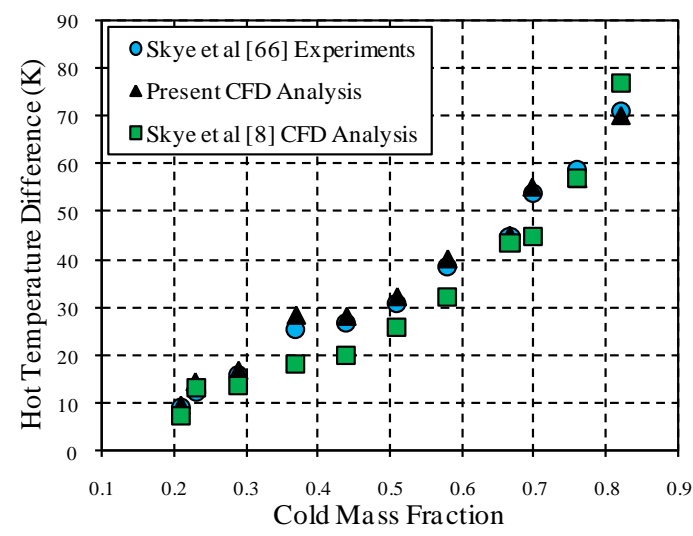

Figure 9. Temperature separation obtained at a hot outlet
In hot exit region as shown in Figure 9, minimum temperature separation in the hot outlet is observed at the cold mass fraction of $\alpha=0.2$. With the addition of cold mass fraction in cold exit, temperature separation in hot outlet increases with an ascending rate so that in the mass fraction of $\alpha=0.81$ in cold outlet, temperature separation increases up to 70 degrees. According to presented diagrams, a great agreement is observed between three-dimensional model and experimental simulation. As can be observed, current three-dimensional simulation works better than two dimensional model of the sky et al. [32] and results especially in the cold outlet have a good correspondence to experimental results.

\section{AIMS AND PROSPECTS OF NUMERICAL RESEARCH}

This numerical research proceeds to influence of injection nozzle dimensions on performance and temperature separation in the vortex tube. For this purpose, device performance in different nozzle dimensions such as length, width, and height of injection nozzle is investigated and most efficient conditions for vortex tube will be selected. We should mention that during this study, results and related diagrams are investigated and discussed in details. Below concepts are frequently used in research: The cold gas mass fraction which is defined as the ratio of mass flow rate from the cold exit to inlet mass flow rate through nozzles is determined as below:

$\alpha=\frac{m_{c}}{m_{i}}$

$\alpha$ varies between 0 and 1 . Overall separation or vortex tube performance is defined as a temperature difference between cold flow outlet and hot control valve:

$\Delta T_{h, c}=T_{h}-T_{c}$

Temperature separation in cold outlet which is the main criterion for determining the cooling performance of vortex tube is described as the temperature difference between inlet nozzles and cold outlet:

$\Delta T_{i, c}=T_{i}-T_{c}$

Temperature separation in the hot outlet is considered as the temperature difference between inlet gas flow to vortex tube through nozzles and gas outlet flow through hot exit end control valve:

$\Delta T_{h, i}=T_{h}-T_{i}$

\section{RESULTS AND DISCUSSIONS}

Vortex tube and its performance were introduced and as stated, the geometric shape of nozzles in vortex tube is one of the most effective parameters on vortex tube efficiency. Many studies about the effect of nozzle parameter and its number on vortex tube efficiency are done and results show the addition of temperature separation followed by increasing number of nozzles. We avoid repeating past introduction and numerically investigate the influence of a new factor about injection nozzles in a vortex tube sample made by Ex-air Co. which is 
experimented by sky et al. [32] and its experimental results already exist. This parameter is obtained by the ratio of $\mathrm{B}$ (width of the nozzle) and $\mathrm{W}$ (length of the nozzle) and we name this dimensionless parameter $(\eta)$. In this numerical study, we first check height and width simultaneously and after finding an efficient quantity for height, proceed to investigate nozzles width and find an efficient amount for it. The main purpose is reducing cold outlet temperature to the minimum possible amount. For this purpose, we equip different dimensions of nozzles to vortex tube and compare results with sky et al. [32] model. All geometric parameters, inlet flow and boundary conditions in both models are the same and only geometric dimensions of the nozzle are variable. This work is executed on an experimental model of reference [32].

\subsection{Influence of nozzle height and width}

In this case study, we first check outlet temperature for different amounts of $\mathrm{W}$ and $\mathrm{H}$ while $\mathrm{B}$ is assumed constant and equal to $0.97 \mathrm{~mm}$. In table 2, results granted for $\mathrm{H}$ equal to 5 , 6 , and $7 \mathrm{~mm}$ and for $\mathrm{W}$ equal to $0.8,0.9,1.0$ and 1.2.

Table 2. The cooling temperature for different nozzle heights

\begin{tabular}{cccc}
\hline W & $\begin{array}{c}\text { Cold exit } \\
\text { temperature } \\
(\mathbf{H = 5} \mathbf{~ m m})\end{array}$ & $\begin{array}{c}\text { Cold exit } \\
\text { temperature } \\
(\mathbf{H = 6} \mathbf{~ m m})\end{array}$ & $\begin{array}{c}\text { Cold exit } \\
\text { temperature } \\
(\mathbf{H = 7} \mathbf{~ m m})\end{array}$ \\
\hline 0.8 & 247.7056 & 247.4873 & 247.6111 \\
\hline 0.9 & 249.2323 & 249.1686 & 249.5124 \\
\hline 1.0 & 249.7434 & 249.6897 & 249.7741 \\
\hline 1.2 & 252.4737 & 252.3642 & 252.4112 \\
\hline
\end{tabular}

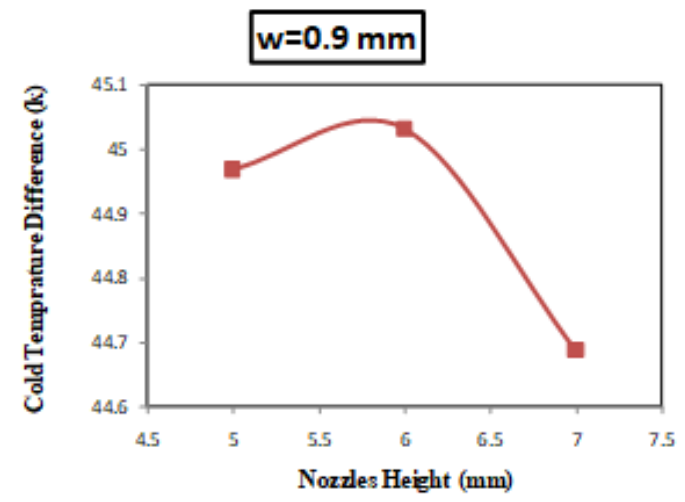

Figure 10. The cold outlet temperature diagram is based on the nozzle height for $\mathrm{w}=0.9 \mathrm{~mm}$

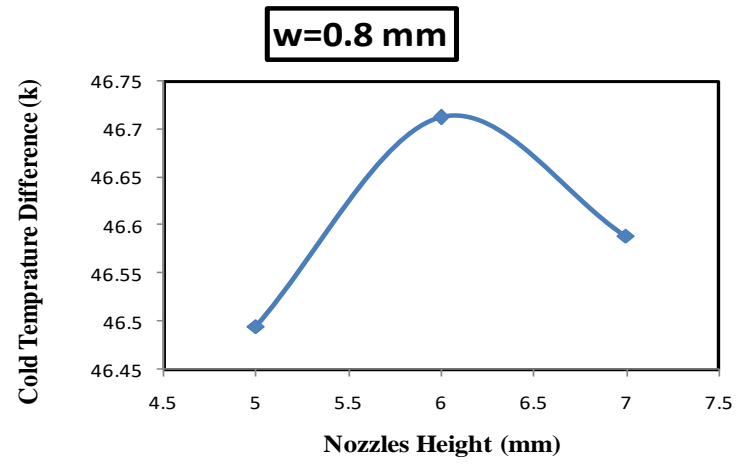

Figure 11. The cold outlet temperature diagram is based on the nozzle height for $\mathrm{w}=0.8 \mathrm{~mm}$
As results show in Figure 10-13, a variation of nozzle height (H) with constant cross-section area wasn't so effective on the temperature difference, so that minimum cold outlet temperature is obtained for $\mathrm{H}=6$ and $\mathrm{W}=0.8,0.9,1$ and 1.2 $\mathrm{mm}$.

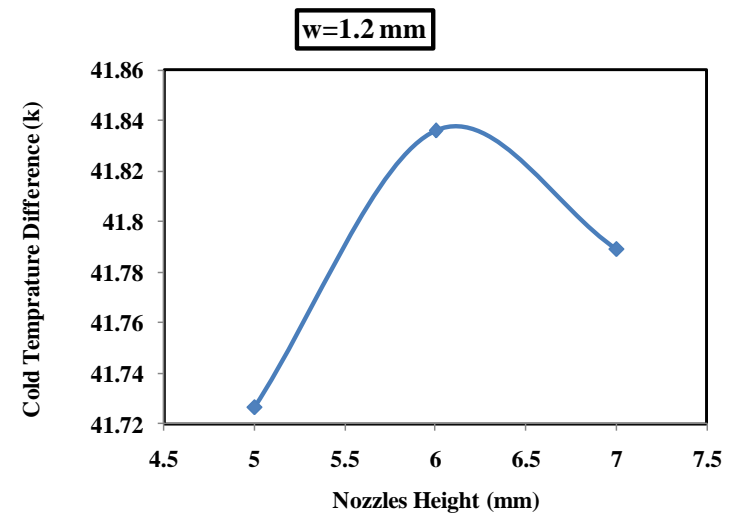

Figure 12. The cold outlet temperature diagram is based on the nozzle height for $\mathrm{w}=1.2 \mathrm{~mm}$

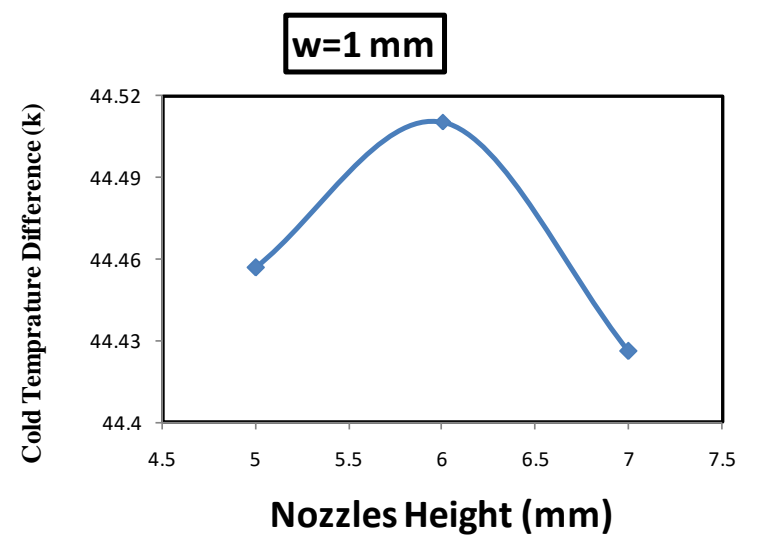

Figure 13. The cold outlet temperature diagram is based on the nozzle height for $\mathrm{w}=1 \mathrm{~mm}$

In addition to cold outlet temperature difference, we can analyze temperature difference in the hot outlet and technically check out vortex tube warming performance. This case study is done in Figure 14 (b). According to this figure model with $\mathrm{W}=0.8 \mathrm{~mm}$, generates the highest temperature difference in the hot outlet with respect to other models. Exactly same conclusion for $\Delta \mathrm{Ti}, \mathrm{c}$ but it is minimum in a model with $\mathrm{W}=1.2 \mathrm{~mm}$. For heating purposes, using a model with properties $\mathrm{H}=7 \mathrm{~mm}, \mathrm{~W}=0.8 \mathrm{~mm}$ and $\mathrm{B}=0.97 \mathrm{~mm}$ are recommended. As mentioned before vortex tube is commonly used for cooling purposes and this paper aims to access the least temperature possible in cold outlet and enhance cooling effect so hot outlet results are brought for more study. As observed in Figure 15 (a-c), for different amounts of $\mathrm{H}$ with nozzle constant cross-section area and constant inlet flow, air flow velocity in nozzle remains constant. This figures out that nozzle length is slightly effective and longer nozzles will bring more loss; while increasing velocity is highly effective to reduce cold outlet temperature. For shorter nozzles, air has less time to become uniform and it makes turbulence in entering the circulation chamber, so an efficient condition is expected for each amount of $\mathrm{W}$. To prove this idea, we proceed to check each condition and demonstrate results as diagrams in Figure 
15 (a-c). If we look closely, we will figure out that height of nozzle equal to $6 \mathrm{~mm}$ brings the most desired result for all width and reduces cold outlet temperature to a minimum.

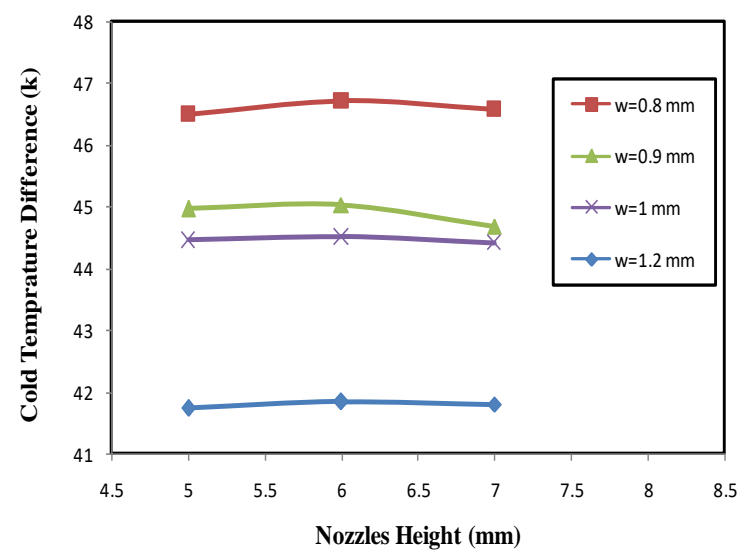

(a)

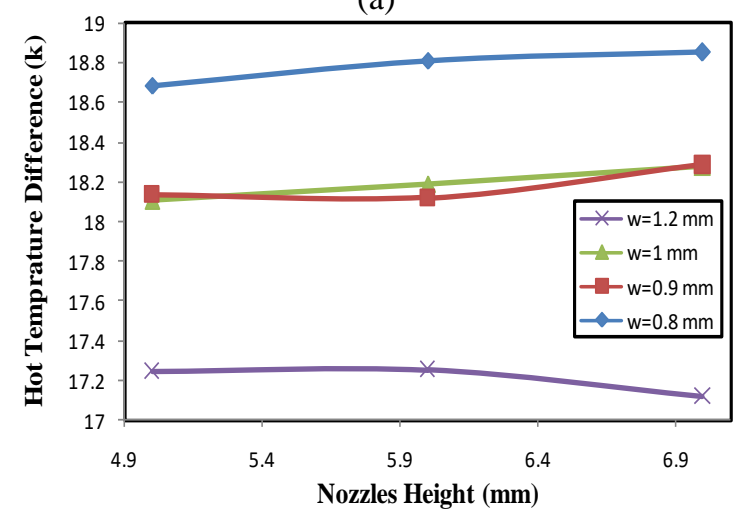

(b)

Figure 14. Comparison diagram of temperature separation at $\alpha=0.3$ in terms of nozzle height for different nozzle wide in

(a) cold output and (b) hot outlet

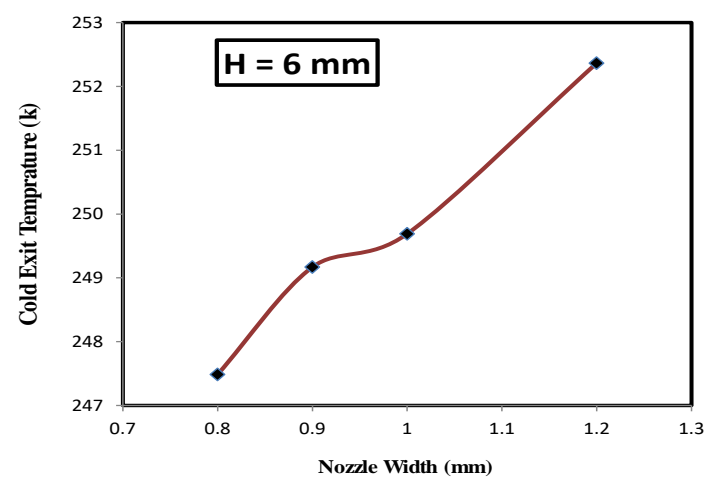

(a)

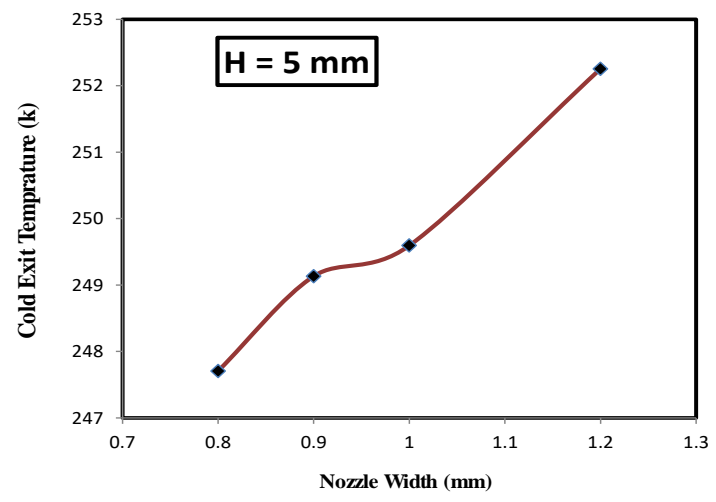

(b)

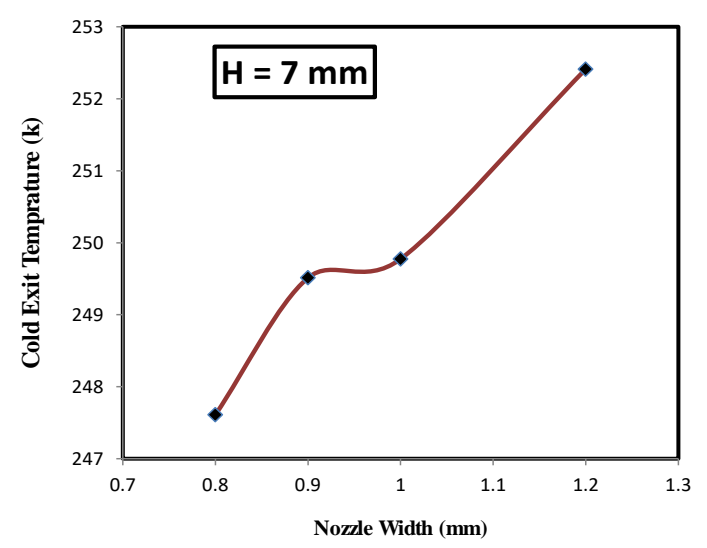

(c)

Figure 15. Cold outlet temperature in terms of nozzle width for different nozzle height

Temperature contours for best condition $(\mathrm{W}=0.8 \mathrm{~mm}$ and $\mathrm{H}=6 \mathrm{~mm})$ and worst condition $(\mathrm{W}=1.2 \mathrm{~mm}$ and $\mathrm{H}=7 \mathrm{~mm})$ are shown in Figure $16(\mathrm{a}, \mathrm{b})$. As can be seen, a model with optimized dimensions for nozzles has lower temperature range near cold exit end with respect to another case. This indicates that correct geometric dimensions help the generation of strong cold flow in the central core.
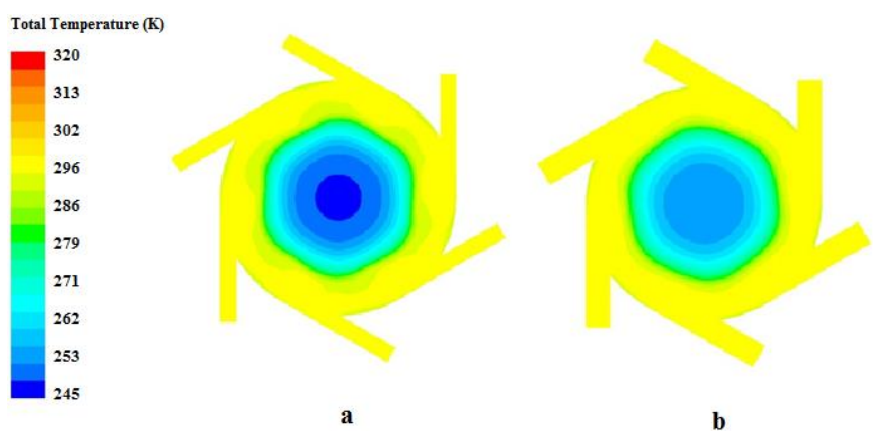

Figure 16. Temperature Contours for different conditions ((a) Optimal mode: $\mathrm{W}=0.8 \mathrm{~mm}$ and $\mathrm{H}=6 \mathrm{~mm}$ (b) Worst case: $\mathrm{W}=1.2 \mathrm{~mm}$ and $\mathrm{H}=7 \mathrm{~mm}$ )

\subsection{Reversed flow in the vortex tube}

An important part of this study is a generation of reversed flow in the vortex tube cold exit. For lower and higher quantities of calculated $(\mathrm{H})$, corresponding temperatures are not illustrated because we face reversed flow for these cases so it requires a brief description of reversed flow in vortex tubes. Reversed flow changes flow pattern near a cold outlet and increases cold outlet temperature by combination and consequently, reduces temperature separation in cold outlet while the desired performance of vortex tube is gaining lowest temperature in cold exit. Figure 17 shows numerical analysis results of reversed flow in cold exit. Flow lines are observed as axial velocity vectors in this figure. In the middle region of cold outlet orifice, the flow direction is toward inside while side flow direction is toward outside. This phenomenon drifts separated cold flow toward the inside of vortex tube and mixing of hot and cold air occurs; therefore, temperature increment at the cold exit is observed, as can be seen in Figure 18.

We were facing this issue in the current study and in numerical simulations for different length and width of 
injection nozzles. The physical aspect of the study was not reasonable because of reversed flow so we avoided investigation of cases with the reversed flow.

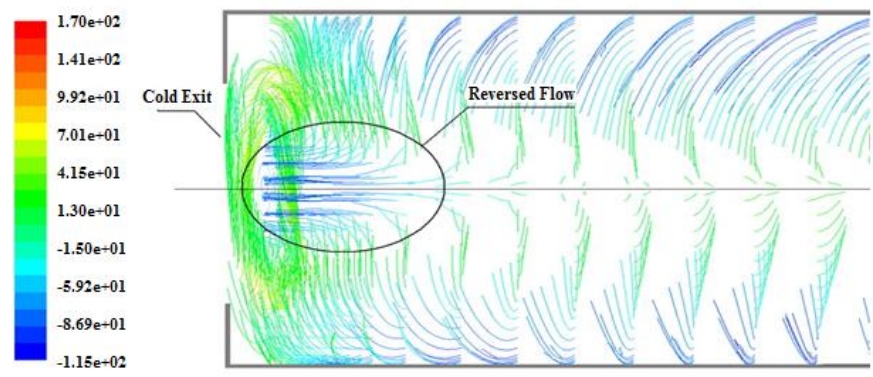

Pathlines Colored by Axial Velocity $(\mathrm{m} / \mathrm{s})$

Figure 17. Two-dimensional display of route paths near cold output in terms of axial velocity and reversed flow

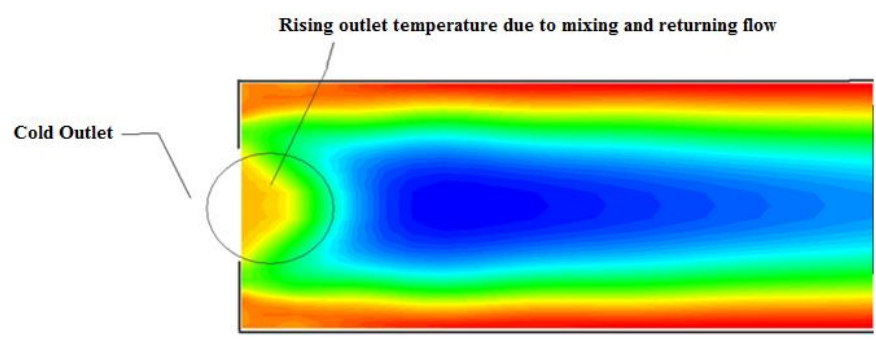

Figure 18. The total temperature range at a cross-section near the cold outlet

\subsection{Mach number}

For better comparison of phenomena inside vortex chamber, Figure 19 shows Mach number distribution within the vortex tube circulation chamber for three different cases. Apparently, Mach number increases with a decrement of nozzle width. The increment of Mach number is followed by addition of velocity and injected momentum to the tube and it increases heat transfer between inner and outer vortexes and cold outlet decreases, which means better temperature separation. As Figure 19 shows, inlet flow in the nozzle is Subsonic but at high Mach (0.9). Mach number increases with movement of fluid through nozzle and entrance to vortex chamber which creates supersonic flow. According to fluid motion through the nozzle and entering the vortex chamber, Mach number increases after reaching to its maximum amount and suddenly flow becomes subsonic which explains a shock inside vortex chamber with losses such as pressure in the system.
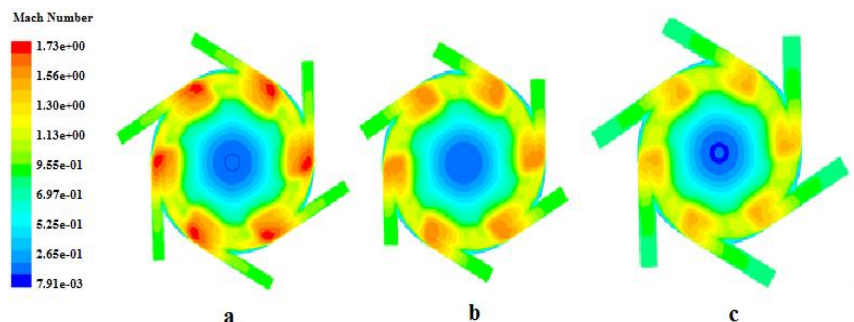

Figure 19. Mach's contours with different scenarios for phase one ((a) Optimal mode: $\mathrm{W}=0.8 \mathrm{~mm}$ and $\mathrm{H}=6 \mathrm{~mm}$ (b) an intermediate state; here $\mathrm{W}=1 \mathrm{~mm}$ and $\mathrm{H}=5 \mathrm{~mm}$ (c) The worst case: $\mathrm{W}=1.2 \mathrm{~mm}$ and $\mathrm{H}=7 \mathrm{~mm}$ )
10.4 Analysis of vortex chamber and cold outlet temperature

In the current numerical investigation, dimensions of injection nozzles are discussed. As can be seen, we investigated fluids behavior by applying variations on length (B) and width (W) for specific injection nozzle height assuming constant inlet cross-section area. Now, we proceed to check out the effect of nozzle width (W) on the pressure inside vortex chamber and in the radial direction by choosing $\mathrm{B}=0.97 \mathrm{~mm}$ for three nozzle heights of $\mathrm{H}=5,6$ and 7 . This shows that reducing $\mathrm{W}$ to a specific amount gets better results for the device. Related diagrams are drawn in Figure 20-22.

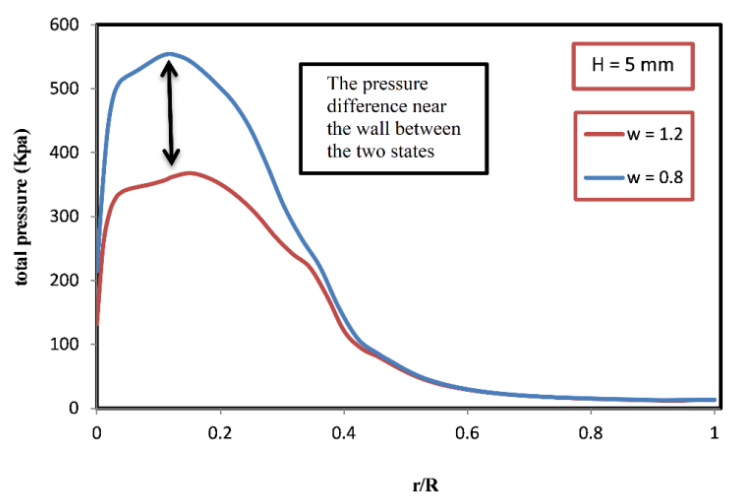

Figure 20. Chart of pressure changes in radial direction for height 5 and for the width of the nozzle 0.8 and $1.2 \mathrm{~mm}$ in the rotary enclosure

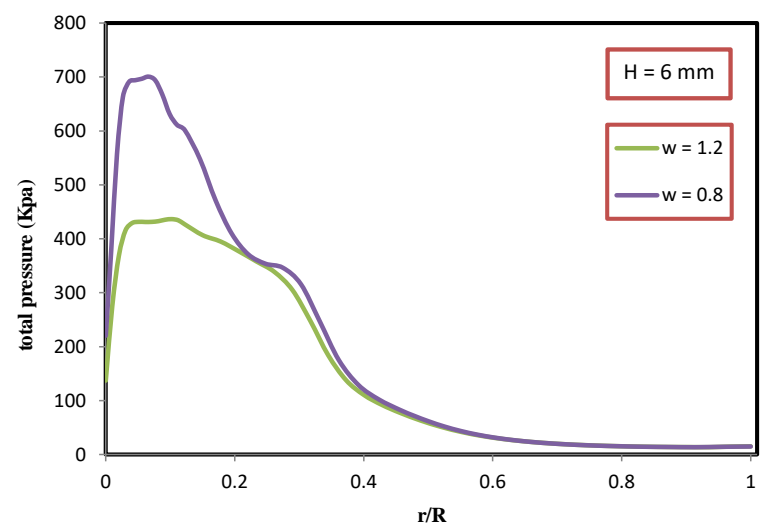

Figure. 21. The diagram changes the pressure in a radial direction for the height of 6 and for the width of the nozzle 0.8 and $1.2 \mathrm{~mm}$ in the rotary enclosure

Observing diagrams 20, 21 and 22 shows that by reducing nozzle width, Compaction beside wall highly grows and pressure corresponding to these points significantly varies, so that inlet pressure for optimized condition $(\mathrm{H}=6 \mathrm{~mm}, \mathrm{~W}=0.8$ $\mathrm{mm}$ ) is equal to 4.8 bar which after injection inside chamber increases up to 7.01 bar. With the reduction of nozzle width, Compaction beside vortex chamber wall is decreased and pressure grows then within this process, more volume is generated for the creation of cold core and gains the ability to expand radially and consequently, this expansion is followed by pressure decrease in cold core. With decrement of cold core reduction near the cold exit according to results; which means that with moving in $\mathrm{Z}$ axis and the radial direction, we observe 
energy separation and this phenomenon causes more temperature difference between cold and hot outlet and also more temperature separation for the device. In order to better conceive, Table 3 presents maximum pressure inside vortex chamber and outlet temperature for different cases and we clearly observe the effect of nozzle width variation on pressure and the outlet temperature of the instrument.

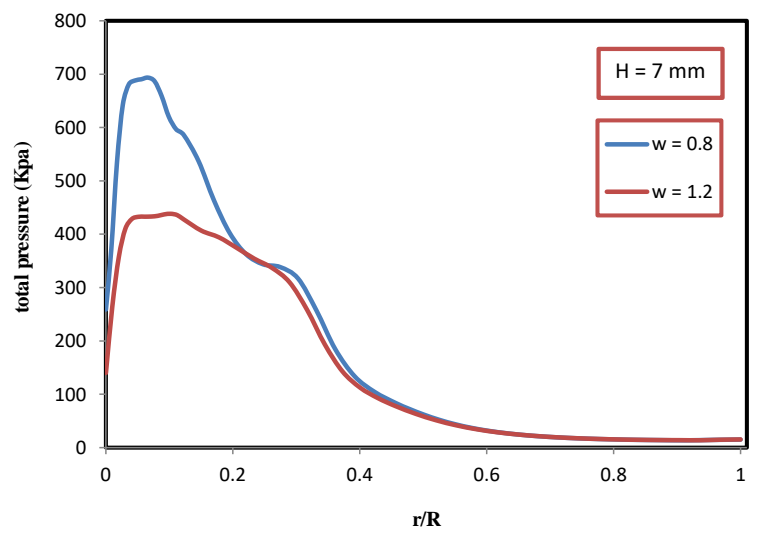

Figure 22. Chart of pressure changes in the radial direction for height $\mathrm{H}=7$ and for the width of the nozzle 0.8 and 1.2 $\mathrm{mm}$ in the rotary enclosure

Table 3. Maximum pressure values in the rotary enclosure and the cold output temperature of the device

\begin{tabular}{|c|c|c|c|}
\hline & & $\begin{array}{c}\text { Total pressure ( } \\
\text { KPa ) }\end{array}$ & $\begin{array}{c}\text { cold exit } \\
\text { temperature }(K)\end{array}$ \\
\hline \multirow{2}{*}{$\begin{array}{c}\mathrm{H}=5 \\
\mathrm{~mm}\end{array}$} & $\begin{array}{c}\mathrm{W}=0.8 \\
\mathrm{~mm}\end{array}$ & 554 & 247.7056 \\
\hline & $\begin{array}{c}\mathrm{W}=1.2 \\
\mathrm{~mm}\end{array}$ & 368 & 252.2537 \\
\hline \multirow{2}{*}{$\begin{array}{c}\mathrm{H}=6 \\
\mathrm{~mm}\end{array}$} & $\begin{array}{c}\mathrm{W}=0.8 \\
\mathrm{~mm}\end{array}$ & 701 & 247.4873 \\
\hline & $\begin{array}{c}\mathrm{W}=1.2 \\
\mathrm{~mm}\end{array}$ & 436 & 252.3642 \\
\hline \multirow{2}{*}{$\begin{array}{c}\mathrm{H}=7 \\
\mathrm{~mm}\end{array}$} & $\begin{array}{c}\mathrm{W}=0.8 \\
\mathrm{~mm}\end{array}$ & 693 & 247.6111 \\
\hline & $\begin{array}{c}\mathrm{W}=1.2 \\
\mathrm{~mm}\end{array}$ & 438 & 252.4112 \\
\hline
\end{tabular}
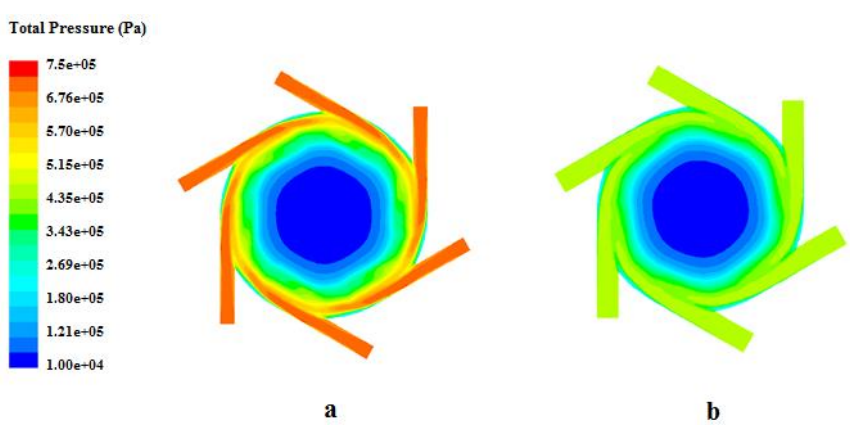

Figure 23. (a) Pressure Contour for the rotary enclosure for $0.8 \mathrm{~mm}$ nozzle width (b) pressure Contour for the rotary enclosure for $1.2 \mathrm{~mm}$ nozzle width

For instance, for nozzle height of $6 \mathrm{~mm}$ and nozzle width 0.8 , the maximum pressure in vortex chamber equals $701 \mathrm{KPa}$ and corresponding cold outlet temperature is $247.48 \mathrm{~K}$, in comparison with $1.2 \mathrm{~mm}$ of nozzle width which has a maximum pressure of $436 \mathrm{KPa}$ and corresponding temperature of 252.36. As results show, for nozzle height of $6 \mathrm{~mm}$ and width amounts of 0.8 and $1.2 \mathrm{~mm}$, pressure difference is equal to $265 \mathrm{KPa}$, while corresponding temperature difference is 4.9 $\mathrm{K}$. This comparison shows that reduction of nozzle width makes pressure inside vortex chamber closer to the wall and increases it quantitatively. Consequently, we reduce the cold outlet temperature device. Contours in Figure 23 are brought to show the effect of nozzle width for $\mathrm{W}=0.8 \mathrm{~mm}$ and $\mathrm{W}=1.2$ $\mathrm{mm}$ and clarify the difference between two indicated cases.

\subsection{Analysis of rectangular cross-section area on cooling temperature separation}

In this section, optimized calculated height $(\mathrm{H}=6 \mathrm{~mm})$ will be used. The purpose is to optimize dimensions of inlet nozzle cross-section area, which means cross-section area is assumed constant and for $\mathrm{B}^{*} \mathrm{~W}=$ constant, results for optimized dimensions for $\mathrm{B}$ and $\mathrm{W}$ are extracted. Therefore, another bounding relation is required so we define a dimensionless parameter symbolized with $(\eta)$ which equal to the division of $\mathrm{B}$ on $\mathrm{W}$ then we analyze results based on the new parameter. As can be observed in Table 4, we proceed to investigate temperature difference in the cold outlet $(\Delta \mathrm{T} i, \mathrm{c})$ for different amounts of $(\eta)$ and higher temperature separation is an approach to desired performance.

Table 4. Separation of cold outlet temperature for different ratios $\eta=B / W$ for $\mathrm{H}=6 \mathrm{~mm}$

\begin{tabular}{cccc}
\hline $\mathbf{B}(\mathbf{m m})$ & $\mathbf{W}(\mathbf{m m})$ & $\mathbf{H}$ & $\boldsymbol{\Delta} \mathbf{T}_{\mathbf{i}, \mathbf{c}}$ \\
\hline 0.88 & 0.88 & 1 & 45.94 \\
\hline 0.97 & 0.8 & 1.21 & 46.7127 \\
\hline 1.108 & 0.7 & 1.58 & 46.3253 \\
\hline 1.293 & 0.6 & 2.15 & 46.5056 \\
\hline 1.464 & 0.53 & 2.76 & 45.857 \\
\hline 1.94 & 0.4 & 4.85 & 44.6182 \\
\hline
\end{tabular}

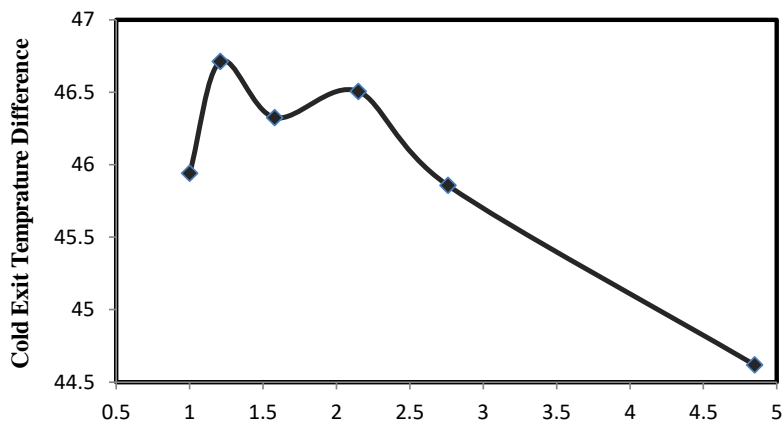

Figure 24. The difference in cold outlet temperature with the input of the device in terms of $\eta$

Figure 24 shows temperature separation for different amounts of $\eta$. Results state that temperature separation decreases with the addition of $\eta$ parameter. This procedure is ascending from 1 to 1.21 then has a relative minimum in interval 1.21 to 2.15 and after that proceeds to descend. Results show that optimized condition occurs in $\eta$ equal to 1.21 .

\subsection{Temperature distribution and path lines}

Figure 25 displays overall temperature distribution pattern through whole tube length for a model with 8.34 grams per 
second flow with $\eta=1.21$ as best condition for cold outlet temperature separation. Maximum amounts for total temperature are observed near vortex tube wall and overall temperature at walls increases due to no-slip condition. In tube central core, the temperature is lower than walls and temperature decreases with fluids motion from hot exit end to cold exit. In this figure, temperature increment is observed in a radial direction toward vortex tube wall.

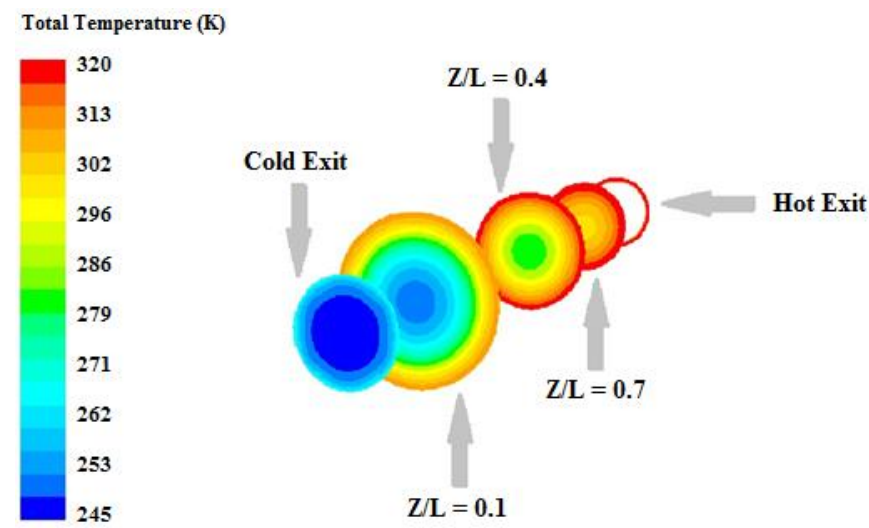

Figure 25. Temperature contour in Kelvin at various sections of the Vortex tube for input $8.34 \mathrm{~g} / \mathrm{s}^{-1}$

Overall temperature contour for vortex tube in cold mass fraction of $\alpha=0.3$ demonstrates that maximum temperature of the hot gas outlet is equal to $329.65 \mathrm{~K}$ and the minimum cold gas temperature is equal to $247.49 \mathrm{~K}$. Total temperature variation shows that reduction of the total temperature gradient is near the hot outlet regions. Path lines for fluid elements in cold mass fraction of $\alpha=0.3$ are shown in three dimensional coordinate in Figure 26. Fluid elements exiting from the cold outlet, head to the end of vortex tube with a swirling motion. Part of fluid elements move through tube length early and the remaining travel to the end of vortex tube then change their direction near tube end and begin their motion toward cold exit end and during this path, their swirling motion is reduced. Another part of fluid elements flows toward hot outlet with a swirling motion in the peripheral region after entering the vortex tube. It is observed that interaction between hot and cold outlet flow occurs at a distance before the cold outlet. Therefore, most of the energy separation is generated before this point. According to obtained path lines, it is clear that in low cold mass fractions, reversed flow toward cold outlet occurs at the hot exit end.

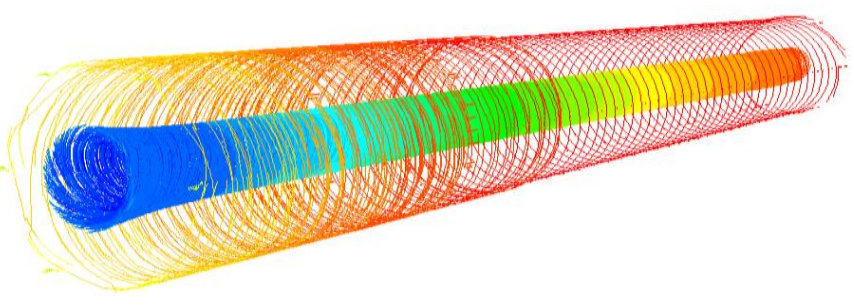

Figure 26. Route lines for fluid on the vortex tube in terms of total temperature

\subsection{Circulation velocity component and its maximum amount}

Circulation velocity has a significant role in energy separation in vortex tubes. On the other hand, studying swirling velocity in different directions of vortex tube (radial and axial directions) can lead us to a good conception of energy separation within the device. For this purpose, in this section, we study this type of velocity profile in Figure 27 at $\mathrm{Z} / \mathrm{L}=0.1$ of tube length and in the radial direction for an optimized model of the sky et al. [32]. As Figure 27 shows, creating optimized nozzle increases circulation velocity besides walls with respect to the common model of sky et.al. [32], but they have no significant difference in other parameters. Maximum circulation velocity is generated near vortex tube wall and decreases toward the hot exit. Variations of swirling velocity in radial direction indicate the existence of free vortexes and completely agree with Kurosaka and Gutsol reports. We should remind that thickness of regions directed by free vortexes regime is very low in the flow field. Therefore the major amount of flow in vortex tube is directed by forced vortexes regime and within these regions, velocity is directly proportional to radius.

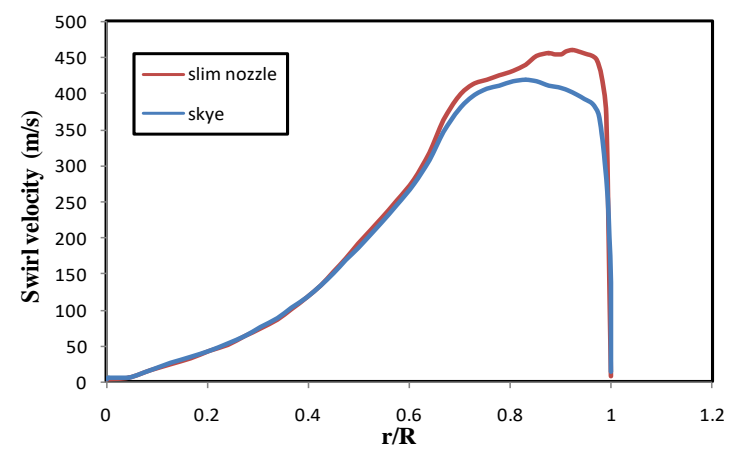

Figure 27. Creating optimized nozzle increases swirling velocity besides walls

\subsection{The rate of cooling and heating power}

Another parameter in temperature separation is the rate of cooling and heating power. If we consider $Q_{c}$ as cooling power and $Q_{h}$ as heating power, their value can be determined by equations (66) and (67).

$Q_{c}=m_{c} c_{p}\left(T_{i}-T_{c}\right)$

$Q_{h}=m_{h} c_{p}\left(T_{h}-T_{i}\right)$

Values for $Q_{h}$ and $Q_{c}$ are shown in Figure (28) and (39).

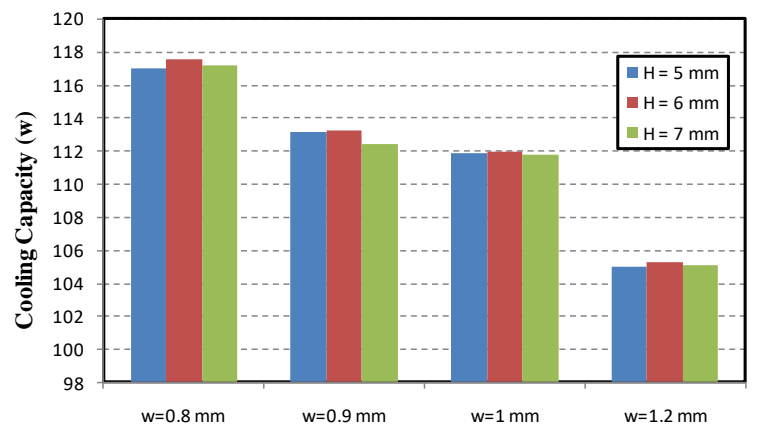

Figure 28. Cooling power

As shown in Figure (28), the value of varies from 105.22 to 117.48 Watt for $\mathrm{H}=6 \mathrm{~mm}$ and owns maximum cooling power for all quantities of w. For $Q_{h}$, a model with nozzle height 
equals to $7 \mathrm{~mm}$ has maximum heating in all conditions except $\mathrm{w}=1.2 \mathrm{~mm}$ (Figure 29). In both cooling and heating conditions, for any amount of $\mathrm{w}$, quantities are so close and this indicates that $\mathrm{H}$ variation has no significant influence on $Q_{h}$ and $Q_{c}$. This fact states that vortex tube is commonly used for local cooling or heating instead of extensive volume.

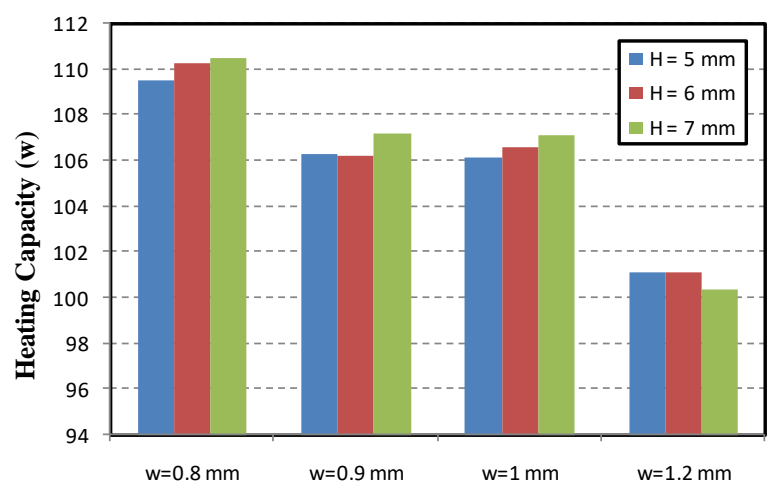

Figure 29. Heating power

\subsection{Mach number analysis and the total pressure in optimized model and model by sky et al. [32]}

In this section, we want to investigate the influence of using a narrow nozzle on stream Mach number in the radial direction, so we drew the diagram of Mach number variations in $\mathrm{z} / \mathrm{L}=0.1$ for both optimized model and model by sky et al. [32] in Figure 30. It is observed that for both conditions, Mach number increases in r-direction and is more than 1 near walls and causes shockwaves beside walls, so flow is subsonic near tube center and supersonic near the wall. With more focus on the diagram, we find out that optimized model has more Mach number near walls (same as a conclusion for swirling velocity in the last section). Addition of Mach number increases velocity and causes momentum increment, therefore air outlet temperature is further reduced but in other radial sections makes no worthy difference.

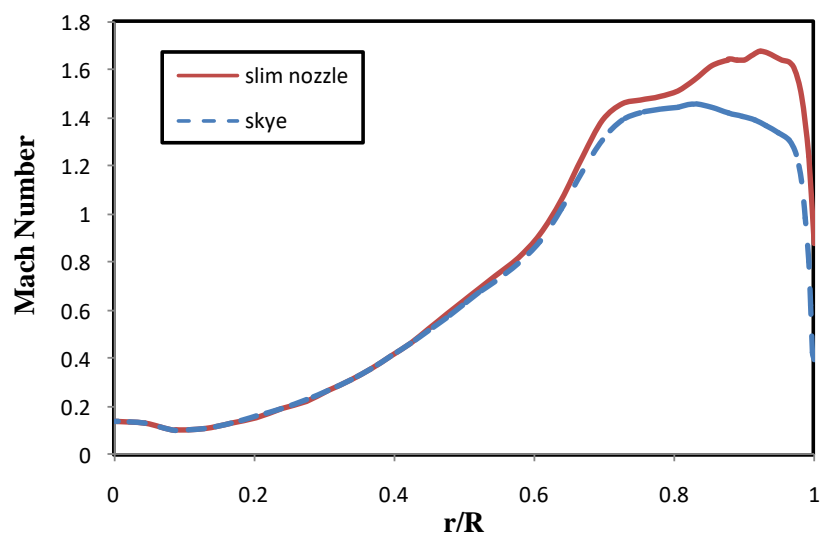

Figure 30. Diagram of Mach number variations in $\mathrm{z} / \mathrm{L}=0.1$ for both optimized model and model by sky and partners [32]

Total pressure variation for both optimized and sky et.al. [32] model is shown in Figure 31. Total pressure is reduced in pipe length through the hot exit. Overall pressure in the radial direction for all sections increases such that pressure in vortex tube perimeter is 4 or 6 times more than total pressure in the middle region. The pressure difference between peripheral and inner layers decreases with further axial distance from inlet region. Using optimized nozzle shows total pressure increment near walls with respect to the sky et al. [32] model.

Results of numerical analysis model by sky et al. [32] and optimized model for maximum temperature separation in tube length, is shown in Figure 32. This diagram shows temperature separation in center of vortex tube and we observe maximum separation for all conditions occurs at a short distance before the cold outlet. It is visible that maximum temperature separation in cold outlet is obtained for the optimized model and this value can reach to temperature separation equals to 46.71, while model by sky et al. [32] has a maximum temperature difference of 43.96. Therefore, according to numerical analysis data, inlet area deduction causes the addition of temperature separation with respect to model by sky et al. [32].

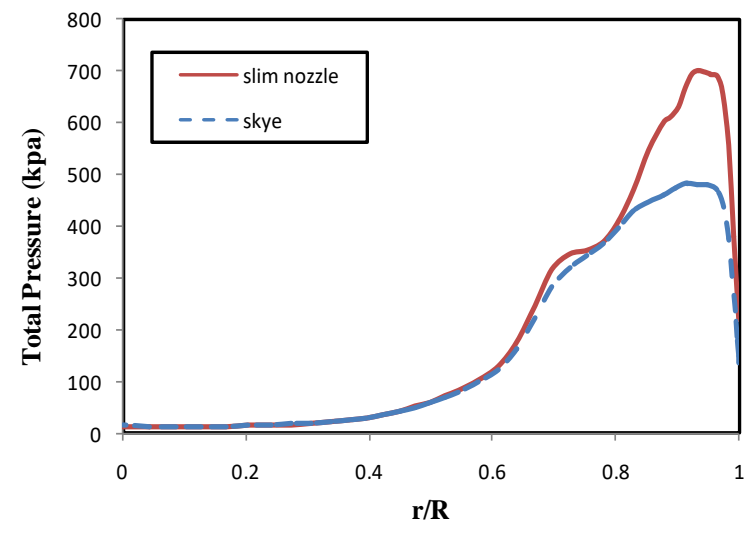

Figure 31. Total pressure variation for both optimized and sky et al. [32] model

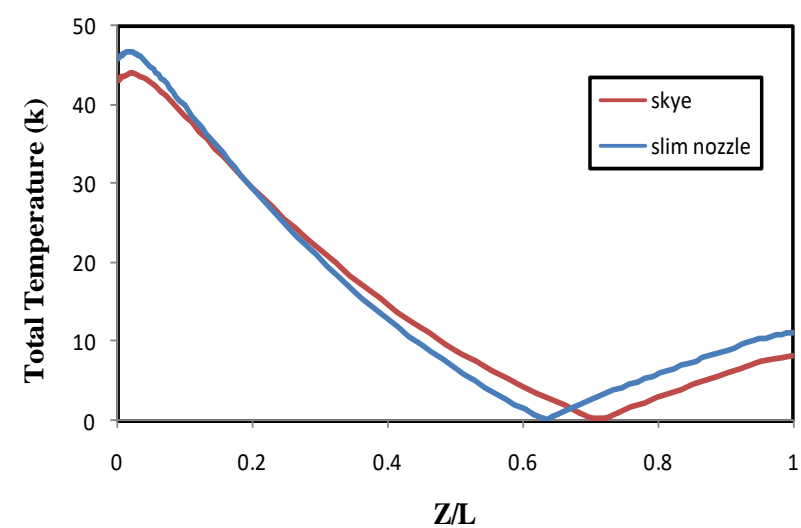

Figure 32. Results of numerical analysis for the model by sky et al. [32] and optimized model for maximum temperature separation in tube length

\section{CONCLUSION}

Although performing mechanism and energy separation in vortex tube is still unknown, it is already manufactured for different industrial applications and its applicability is more revealed in different industries. In this numerical study a wide range of vital parameters on performance for energy separation optimization was investigated and analyzed, and efficient parameters were designed and introduced. It is notable that this vortex tube was specified for the cooling application. Many parameters affect vortex tube performance 
which variation in any of them can lead to change in energy separation and flow pattern in this device. Mass flow ratio in cold outlet, number of inlet nozzles, cold outlet diameter, the ratio of length to diameter of the vortex tube, pressure, inlet temperature and etc. are such parameters which play the vital role in energy separation phenomenon in the vortex tube. The accurate study of flow pattern and vortex tube geometric characteristics in fluid dynamics can help a lot in optimized design of this device. A brief of results was presented below:

- Results showed that CFD is useful to save time and energy in complex flow fields and inharmonic geometries.

-According to high change in affecting variations on flow field and high turbulence of flow regime inside vortex tube, we should apply a tiny network.

- Results state that cold flow mass fraction is the most vital parameter in controlling cold and hot outlet. For cooling purpose, applying cold mass fractions about 0.3 causes higher separation in cold outlet and cold mass fraction 0.8 is recommended for heating.

- Results of numerical simulation for temperature separation indicate a great agreement with experimental results.

-In low mass fractions of the cold outlet, CFD model shows a reverse flow in cold airflow outlet which reverse flow temperature should be determined in each iteration in order to simulate. According to obtained result, assuming an average temperature of overall cold outlet stream for reverse flow has more accurate results with respect to constant temperature assumption for reverse flow.

- Optimization of nozzle dimensions in fixed condition increases temperature separation and obtains the desired result with no excess cost.

- Nozzle height variation is not such effective parameter on temperature separation of vortex tube but the change in nozzle width shows a great effect on separation such that temperature of sky et.al. The vortex tube is reduced by 5 degrees with optimizing nozzle dimensions.

- Results state that temperature separation decreases with increasing parameter $(\eta)$. This process is increasing in 1 to 1.21 interval then has relative minimum from 1.21 to 2.15 then continues to decrease. First, it was expected that decreasing $(\eta)$ gain a better temperature separation but results show that efficient condition occurs in ( $\eta$ ) equal to 1.21 .

-With the reduction of nozzle width, compression near vortex chamber wall decreases, and pressure grows and compresses. In consequence, higher volume is provided for the formation of cold core and takes the ability to expand radially and this expansion will result in pressure reduction in cold core and we will observe decrement of cold core temperature.

-Model with dimensions $\mathrm{H}=7 \mathrm{~mm}, \mathrm{~W}=0.8 \mathrm{~mm}$, and $\mathrm{B}=0.97$ is recommended for heating purposes.

- Pressure change inside vortex tube results changes in Mach number. Decreasing nozzle width makes pressure inside vortex chamber closer to the wall and increases its value quantitatively and reduces cold outlet temperature in consequence.

- $Q_{c}$ Varies from 105.22 to 117.48 Watt for $\mathrm{H}=6 \mathrm{~mm}$ and owns the highest cooling power for all values of w. For $Q_{h}$, model with nozzle height of $7 \mathrm{~mm}$ has maximum heating in all conditions except when $\mathrm{w}=1.2$.

-The maximum value of swirling velocity is generated near vortex tube wall, and its quantity is reduced toward the hot outlet. Changes in swirling velocity in radial direction show the presence of the free vortex. With making optimized nozzle, values of swirling velocity increase near walls with respect to the usual model of sky et al.; however, in the rest of crosssection have no explicit variation.

- For both optimized and sky model, Mach number increases toward the radial direction and gets higher than 1 near the wall and causes shockwave near the wall, so flow close to tube center is subsonic and supersonic near the wall.

\section{REFERENCES}

[1] Bazgir A. (2017). Ranque-Hilsch vortex tube: A numerical study.

[2] Bazgir A, Heydari A. (2018) Energy conversion (efficiency) of straight counter-flow Ranque-Hilsch Vortex Tube (RHVT) by using optimized turbulence model.

[3] Bazgir A. (2017). Investigation of the effects of number of nozzle intakes on the performance of vortex tube refrigerators base on CFD.

[4] Bazgir A. (2017) Numerical investigation of flow pattern inside different counter-flow Ranque-Hilsch vortex tube refrigerators.

[5] Linderstrom-Lang C. (1967). On gas separation in Ranque-Hilsch vortex tubes. Zeitschrift für $\begin{array}{llll}\text { Naturforschung } & \text { A } & \text { 22(5): }\end{array}$ https://doi.org/10.1515/zna-1967-0537

[6] Marshall J. (1977). Effect of operating conditions, physical size and fluid characteristics on the gas separation performance of a Linderstrom-Lang vortex tube. International Journal of Heat and Mass Transfer 20(3): 227-31. https://doi.org/10.1016/00179310(77)90209-5

[7] Raterman KT, Kellar M, George M, Turner TD, Podgorney AK, Stacey DE, et al. (2001). A vortex contactor for carbon dioxide separations. Idaho National Laboratory (INL).

[8] Kulkarni MR, Sardesai CR. (2002). Enrichment of methane concentration via separation of gases using vortex tubes. Journal of energy engineering 128(1): 1-12. https://doi.org/10.1061/(ASCE)07339402(2002)128:1(1)

[9] Poshernev N, Khodorkov I. (2004). Natural-gas tests on a conical vortex tube (CVT) with external cooling. Chemical and Petroleum Engineering 40(3): 212-7. https://doi.org/10.1023/B:CAPE.0000033678.73190.e8

[10] Takahama H, Kawamura H, Kato S, Yokosawa H. (1979). Performance characteristics of energy separation in a steam-operated vortex tube. International Journal of Engineering Science 17(6): 735-44. https://doi.org/10.1016/0020-7225(79)90048-X

[11] Collins R, Lovelace R. (1979). Experimental study of two-phase propane expanded through the Ranque-Hilsch tube. ASME Journal of Heat Transfer 101(2): 300-5.

[12] Gao C, Bosschaart K, Zeegers J, De Waele A. (2005). Experimental study on a simple Ranque-Hilsch vortex tube. Cryogenics 45(3): 173-83. https://doi.org/10.1016/j.cryogenics.2004.09.004

[13] Eiamsa-ard S, Promvonge P. (2008). Numerical simulation of flow field and temperature separation in a vortex tube. International communications in Heat and Mass $\quad$ Transfer 35(8): 937-47. https://doi.org/10.1016/j.icheatmasstransfer.2008.04.01 0 
[14] Wu Y, Ding Y, Ji Y, Ma C, Ge M. (2007). Modification and experimental research on vortex tube. International Journal of Refrigeration 30(6): 1042-9. https://doi.org/10.1016/j.ijrefrig.2007.01.013

[15] Kirmac1 V, Uluer O. (2009). An experimental investigation of the cold mass fraction, nozzle number, and inlet pressure effects on performance of counter flow vortex tube. Journal of Heat Transfer 131(8): 081701.

[16] Pinar AM, Uluer O, Kirmaci V. (2009). Optimization of counter flow Ranque-Hilsch vortex tube performance using Taguchi method. International Journal of $\begin{array}{ll}\text { Refrigeration } 32(6) \text { : } & \text { 1487-94. }\end{array}$ https://doi.org/10.1016/j.ijrefrig.2009.02.018

[17] Dincer K, Avci A, Baskaya S, Berber A. (2010). Experimental investigation and exergy analysis of the performance of a counter flow Ranque-Hilsch vortex tube with regard to nozzle cross-section areas. International Journal of Refrigeration 33(5): 954-62. https://doi.org/10.1016/j.ijrefrig.2010.03.009

[18] Polat K, Kirmac1 V. (2011). Determining of gas type in counter flow vortex tube using pairwise fisher score attribute reduction method. International Journal of Refrigeration 34(6): 1372-86. https://doi.org/10.1016/j.ijrefrig.2011.05.010

[19] Chang K, Li Q, Zhou G, Li Q. (2011). Experimental investigation of vortex tube refrigerator with a divergent hot tube. International journal of refrigeration 34(1): 3227. https://doi.org/10.1016/j.ijrefrig.2010.09.001

[20] Lewellen W. (1962). A solution for three-dimensional vortex flows with strong circulation. Journal of Fluid Mechanics 14(3): 420-32. https://doi.org/10.1017/S0022112062001330

[21] Ahlborn B, Groves S. (1997). Secondary flow in a vortex tube. Fluid Dynamics Research 21(2): 73-86. http://iopscience.iop.org/article/10.1016/S01695983(97)00003-8/meta

[22] Bramo RA, Pourmahmoud N. (2011). CFD simulation of length to diameter ratio effects on the energy separation in a vortex tube. Thermal Science 15(3): 833-48.

[23] Pourmahmoud N, Bramo AR. (2011). The effect of L/D ratio on the temperature separation in the counter-flow vortex tube. International Journal of Research and Reviews in Applied Sciences 6(1).
[24] Bramo A, Pourmahmoud N. (2010). A numerical study on the effect of length to diameter ratio and stagnation point on the performance of counter flow vortex tube. Aust J Basic \& Appl Sci 4(10).

[25] Shamsoddini R, Nezhad AH. (2010). Numerical analysis of the effects of nozzles number on the flow and power of cooling of a vortex tube. International Journal of Refrigeration 33(4): 774-82. https://doi.org/10.1016/j.ijrefrig.2009.12.029

[26] Akhesmeh S, Pourmahmoud N, Sedgi H. (2008). Numerical study of the temperature separation in the Ranque-Hilsch vortex tube. American Journal of Engineering and Applied Sciences 1(3).

[27] Rafiee SE. (2017). Experimental analysis on heat and mass transfer and separation process inside A DCVT based on pressure distribution. Chemical Engineering Transactions 62: 367-372. https://doi.org/10.3303/CET1762062

[28] Tsutsumi A, Kansha Y. (2017). Thermodynamic mechanism of self-heat recuperative and self-heat recovery heat circulation system for a continuous heating and cooling gas cycle process. Chemical Engineering Transactions 61: 1759-1764. https://doi.org/10.3303/CET1761291

[27] Kurosaka M. (1982). Acoustic streaming in swirling flow and the Ranque-Hilsch (vortex-tube) effect. Journal of Fluid Mechanics 124: 139-72. https://doi.org/10.1017/S0022112082002444

[28] Takahama H, Yokosawa H. (1981). An experimental study of the vortex tube-Where the vortex chamber includes a divergent tube. Nagoya University Faculty Engineering Memoirs 33: 195-208. http://adsabs.harvard.edu/abs/1981NUFEM..33..195T

[29] Takahama H. (1966). Studies on Vortex Tubes (3rd report, variations of velocity, temperature and energy with axial distance, and mechanism of energy separation). Transactions of the Japan Society of Mechanical Engineers 32(235): 503-10. https://doi.org/10.1299/jsme1958.9.121

[30] Skye H, Nellis G, Klein S. (2006). Comparison of CFD analysis to empirical data in a commercial vortex tube. International Journal of Refrigeration 29(1): 71-80. https://doi.org/10.1016/j.ijrefrig.2005.05.004 